\title{
Human Centric E-Learning and the Challenge of Cultural Localization
}

\author{
Albert Badre ${ }^{1}$, Stefano Levialdi ${ }^{2}$, Jim Foley $^{1}$, John Thomas ${ }^{3}$, Carol Strohecker ${ }^{4}$, \\ Antonella De Angeli ${ }^{6}$, Preetha Ram ${ }^{5}$, Ashwin Ram ${ }^{1}$, and Jaime Sanchez ${ }^{7}$ \\ ${ }^{1}$ Georgia Institute of Technology \\ ${ }^{2}$ Dipartimento di Informatica, Universita' di Roma "La Sapienza" \\ ${ }^{3}$ IBM T.J. Watson Research \\ ${ }^{4}$ University of North Carolina \\ ${ }^{5}$ Emory University \\ ${ }^{6}$ University of Manchester' \\ ${ }^{7}$ Universidad de Chile \\ badre@cc.gatech.edu
}

\section{Introduction}

The cutting edge of designing for the user experience today is found in the arena of designing for the user's cultural context $\{1\},\{2\},\{3\}$. This is primarily true because of global expansion of the Internet and Web usage. Brick and mortar businesses have learned to adapt their products to be culturally sensitive. For example, car manufacturers build the same basic platform with different styling and amenities depending on where the vehicle will be sold. To convey an appealing image to potential buyers and readers, publishers translating popular works into many languages usually have different covers designed for different countries: for this reason they aim towards the perception of an object and of its functions. We often differ in the way we experience the world around us. Our experiences differ relative to our primary language, educational practices, work habits, and what makes for an enjoyable experience, whether in what and how we like to play, what sounds that we appreciate, or colors that appeal to us $\{4\},\{5\}$.

\section{E-Learning and the Culture Sensitive Human Centric Challenge}

The increasing interest in on-line learning leads us to seek answers to questions about how to provide virtual learning environments that enhance the learning experience, and at the same time address the needs of the culturally sensitive global learning context of the World Wide Web. More specifically, we look for solutions to questions about making the virtual learning context user compatible, learner effective, and totally accessible (universally usable).

Human-centric e-learning design means designing for the user experience in a specific learning context. Designing for context means constructing suitable learning environments grounded in the learner's learning ecology, be it a classic instructor-led classroom environment, learner-led customized setting, collaborative learning, or knowledge-based tutorials. We know that providing the right context plays a crucial role in learning $\{6\}$. Students who learn and then recall material in the same environment 
with specific contextual cues will perform better than those made to recall in a different environment. Embedded in any context are cultural cues and clues that guide the process of observation and interpretation. The challenge for the interactive e-learning designer is to provide e-learning content and tools that invoke the unique cultural cues of multiple localized, and potentially conflicting contexts, while at the same time allowing for a common virtual learning environment, where virtual learners are having shared content and experience.

The fundamental challenge for the panel is for each panelist to put forward their vision for the future of human-centric virtual learning environments and virtual learning communities. The panel will explore the issue of what "human-centric" in the e-learning environment means, and how to resolve the issue of the seeming conflict between shared learning experience and the need to be culturally sensitive.

More specifically, the panel will be asked to consider the following questions:

1) What makes a virtual learning environment human-centric, and what are the requirements to make such an environment compelling and in high demand by potential participants?

2) Should the emphasis of learner-centered or user-centered, be more on the "learner" or the "user"? Is there a conflict to be resolved between "learner culture" and "user culture"?

3) How do we take cultural usability into account? While e-learning is by practice global, it has to be culturally sensitive to learner's unique environment. How do we reconcile the need for cultural localization with the requirement for universally consistent e-learning content?

4) Describe your vision of an e-learning environment (existing or imaginary) that meets what you consider to be human-centric requirements and culturally sensitive?

5) What are the implications of the growing virtual social networks, for humancentric and culturally sensitive e-learning?

\section{References}

1. Badre, A.N.: Shaping Web Usability: Interaction Design in Context, pp. 213-227. Addison Wesley, Boston (2002)

2. Marcus, A., Gould, E.W.: Cultural Dimensions and Global Web User-Interface Design: What? So What? Now What? In: 6th Conference on Human Factors and the Web in Austin, Texas (June 19, 2000)

3. De Angeli, A., Athavankar, U.A., Joshi, A., Coventry, L., Johnson, G.I.: Introducing ATM's in India: A contextual enquiry. Interacting with Computers special issue. Global human-computer systems 16(1), 29-44 (2004)

4. Marcus, A.: International and Intercultural User-Interface Design. In: Stephanidis, C. (ed.) User Interfaces for All, Lawrence Erlbaum, New York (2000)

5. Hofstede, G.: Cultures and Organizations: Software of the Mind. McGraw-Hill, New York (1997)

6. Godden, D., Baddeley, A.: Context-dependent memory in two natural environments. British Journal of Psychology 81, 465-46 (1975) 